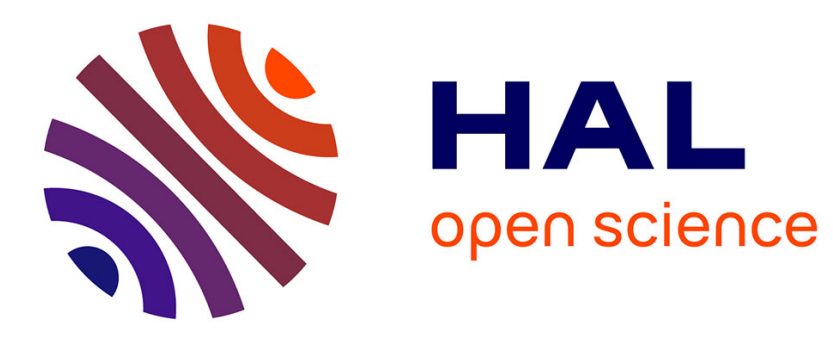

\title{
Intergenerational Joint Media Engagement
}

Ana Carla Amaro, Lidia Oliveira, Vania Baldi

\section{To cite this version:}

Ana Carla Amaro, Lidia Oliveira, Vania Baldi. Intergenerational Joint Media Engagement. 17th International Conference on Entertainment Computing (ICEC), Sep 2018, Poznan, Poland. pp.368373, 10.1007/978-3-319-99426-0_46. hal-02128601

\section{HAL Id: hal-02128601 \\ https://hal.inria.fr/hal-02128601}

Submitted on 14 May 2019

HAL is a multi-disciplinary open access archive for the deposit and dissemination of scientific research documents, whether they are published or not. The documents may come from teaching and research institutions in France or abroad, or from public or private research centers.
L'archive ouverte pluridisciplinaire HAL, est destinée au dépôt et à la diffusion de documents scientifiques de niveau recherche, publiés ou non, émanant des établissements d'enseignement et de recherche français ou étrangers, des laboratoires publics ou privés. 


\title{
Intergenerational Joint Media Engagement:
}

\section{pre-testing interviews, activities and tablet's applications}

\author{
Ana Carla Amaro ${ }^{[0000-0001-7863-5813]}, \underset{0002-7663-3328]}{\text { Lidia Oliveira }}{ }^{[0000-0002-3278-0326]}$ and Vania Baldi ${ }^{[0000-}$ \\ Digimedia - Digital Media and Interaction (CIC.Digital), University of Aveiro, Portugal \\ aamaro@ua.pt凶, lidia@ua.pt, vbaldi@ua.pt
}

\begin{abstract}
This paper presents the results of a preliminary study, in which grandchildren/children and grandparents/middle aged to older adults were observed while interacting with each other and with an App, on a tablet, to develop a proposed activity. Before and after these Joint Media Engagement (JME) sessions, participants were also interviewed, in order to collect data and to assess the perceived impact of the JME sessions in the quality of the intergenerational relationship, on the attitude towards each other and on children and older adults' digital literacy. The main goals of this preliminary study were to validate data collection instruments and techniques, namely the JME sessions activities, Apps and protocols and the pre- and post-JME session interviews' scripts. This preliminary study is part of a research that aims to understand the interactions and communication processes taking place during JME sessions involving grandparents/older adults (over 55 years old) and grandchildren/children (5 to 10 years old) in collaborative usage of tablets and tablets' Apps, in order to develop guidelines for designing mobile contents and Apps to support and promote intergenerational interactions.
\end{abstract}

Keywords: Intergenerational, Older Adults, Grandparents, Children, Mobile, Tablets, Communication, Interaction.

\section{Introduction}

The World is getting old: that's a fact. As reported by [1,2,3], population aging is a worldwide phenomenon, resulting from decreasing mortality and declining fertility, that will continue to grow. In this way, coexistence between generations, namely between grandparents and grandchildren, is becoming more common and lasting for longer periods of time. The age gap between generations often leads to: i) age-segregated beliefs, behaviors and communication practices; ii) the discrediting and waste of each generation knowledge and experiences; and iii) the lack of reciprocal learning and mutual understanding $[4,5]$. 
Research has shown that the promotion of intergenerational relations and contact is crucial, as a way of countering those age gap's issues and ensure the cognitive, emotional and social wellbeing of both children and older adults $[4,6,7,8]$. Quality intergenerational relations and contact between grandparents and grandchildren, particularly, are of extreme importance, being related with more positive behaviors towards older adults and a more effective transition to adulthood (for grandchildren) and a higher social interaction, satisfaction and mental and physical health (for grandparents) $[4,8,9]$.

Studies also suggest that mobile devices and applications (Apps) are particularly appropriated tools to foster intergenerational engagement in playful and educational activities, providing opportunity and facilitating collaboration and cooperation between generations in a range of settings and contexts [10,11]. By using touch screens and enabling gesture-based interaction, these devices allow to overcome interaction barriers and seem to be best suited for supporting intergenerational engagement that goes beyond the technology, happening in the physical environment $[10,12,13]$.

Most research on intergenerational joint media consuming and technology usage has been focused on TV co-viewing by children and parents. More recently, the term Joint Media Engagement (JME) has been coined, extending the concept beyond TV and referring "to spontaneous and designed experiences of people using media together, that can happen anywhere and at any time when there are multiple people interacting together with digital or traditional media" [13]. JME research, however, remains mainly focused on parents and children, rather than on grandparents and grandchildren. In fact, grandparents and grandchildren's intergenerational interactions, generally speaking, are acknowledged as being poorly studied, making informed development of technologies to support them much difficult [14]. We have been conducting research that aims to understand the interactions and communication processes taking place during JME sessions involving grandparents/middle aged (over 55 years old) to older adults, and grandchildren/children (from 5 to 10 years old), in collaborative usage of tablets and tablets' Apps, in order to develop guidelines for designing mobile contents and apps to support and promote intergenerational interactions. This paper, particularly, describes the results of a preliminary study, in which JME sessions between grandchildren/children and grandparents/middle aged to older adults were conducted, along with pre- and post-JME session interviews.

\section{Method}

The preliminary study was exploratory and non-experimental, aiming to validate data collection instruments and techniques. During the study, two pairs of participants, selected through criterion sampling procedures and by convenience, were interviewed and observed in JME sessions, in which they used a particular tablet App to develop a specific activity proposed by the researcher.

In this way, the session with parental related participants involved a 58 years old grandmother and her 5-year's old granddaughter, building their family tree using the App Notes HD on an iPad Mini. The session with the non-parental participants involved 
a 65 years old lady and an 8-year-old boy, jointly drawing the older adult as a child and the child as an older adult, using the App NOTEPAD+ on an iPad Mini.

The proposed activities were thought to be potentially promoters of reciprocal learning and enjoyable by both (grand)children and grandparents/older adults.

A total of two interviews were performed to each element of the pairs, one before and the other after JME sessions, in order to collect data from participants, such as demographic data, level of digital literacy, quality of the intergenerational relationship and attitude towards each other. In the post-JME sessions' interviews, questions were introduced to assess the perceived impact of JME sessions in the quality of the intergenerational relationship, on the attitude towards each other and on children and older adults' digital literacy.

The areas of competence and levels of proficiency proposed by DIGCOMP project $[15,16]$ were used to assess digital literacy of the older participants, understood as the ability to mobilize knowledge, skills and attitudes to critically identify, access, manage, assess and integrate digital resources to build new knowledge and communicate with others, in an effective way and through different formats $[15,16,17,18]$. However, some indicators were added, in order to integrate important skills that were not originally foreseen (e.g., the use of instant messaging services), as well as to incorporate mobilespecific skills (e.g., search for and installing Apps or using geo-location services). In this way, digital literacy indicators were assessed from a set of questions that were gradually and contextually introduced during the pre-JME sessions' interviews, after a brief conversation concerning access to tablets, smartphones and computers. As far as 5 to 10 years old children is concerned, no fully appropriate set of digital literacy's indicators and scales have been found. Therefore, interviews were used to collect as many information as possible concerning what children are able and used to do with mobile devices and computers, considering the same 4 areas of competence used for older adults, and scales are to be deductively developed.

Concerning the quality of intergenerational relationship, indicators were developed based on what the literature suggests to be a well-succeeded relationship: people spend time together; communicate and engage in meaningful and enjoyable activities; participate in each other's life; and, learn reciprocally [4,5]. All these indicators were surveyed through a set of questions integrated into the pre-JME session' interview script and the definitive scales for the quality of intergenerational relationship are to be deducted from results.

Most of the questions in both interviews' scrips were initiation questions, designed to introduce the topics, trigger the very first ideas about them and that could be posed without any specific order, for example: "Did you enjoy the activity? Did you learn/teach anything? What do you think of grandparents and grandchildren using technology together?". These questions were complemented with development and contextual ones, intended to expand or supplement the initially introduced ideas. Regarding the interviews' scripts, the study aimed to verify the adequacy of initiation questions to trigger the collection of the needed data and the duration of the interviews.

The JME sessions took place in the living rooms of the older participants' homes. Participants were seated in the couch and the researcher was seated near them. Sessions 
were recorded using a GoPro HERO4. Both sessions began with a description of the activities by the researcher and a brief introduction to the Apps and their main features. During each session, data collection was performed by direct and participant observation, and, whenever possible and/or desirable, participants were questioned in order to build a shared interpretation of the activities and processes taking place. In what concerns this JME sessions, the study aimed to obtain children and older adults' feedback regarding the proposed activities, as well as the assessment of the adequacy of the selected Apps.

\section{$3 \quad$ Results}

All the initiation questions posed during the pre-JME session interviews, both to children and older participants proved to be effective in triggering the conversation around the indicators of digital literacy and the quality of intergenerational relationship and attitude toward each other. In the same way, no problems were identified in the postJME session interviews made to the older participants. Concerning the (grand)children post-JME session interviews, however, some worrying issues were observed. In fact, even though children have demonstrated an understanding of the questions posed, they mostly provided "yes" or "no" answers, or short and poorly elaborated ones. Although it was explained to them that there were no right or wrong answers and that the important thing was to know their opinion, children were reluctant to answer the development questions requesting argumentation.

Regarding the Grandmother/Grandchild JME session, and after the initial introduction by the researcher, grandmother handed the tablet to the granddaughter, who controlled the interaction with it for most of the time, showing reluctance in letting the tablet go or sometimes moving the tablet away, when grandmother tried to interact. In this way, grandmother's role was more related to the management of tasks, suggesting how the activity should progress, helping with the writing and the positioning of elements on the screen. The version of the App NOTE HD used in this session (free version), proved to be extremely unstable. The App crashed a few times, some of which while undoing inadvertent actions and trying to incorporate a child's photo. Other main problems aroused from the fact that, after inserted into the canvas, elements merge with the background and can no longer be individually manipulated. When not overlapping, elements could be resized and repositioned through pinching, spreading, rotating and dragging that slice of the canvas. Also, the App's drawer menu often interfered with content creation process, leading to inadvertent selection of tools.

In the Boy/Older Lady JME session, the researcher's explanation of the activity immediately triggered a conversation about how old the boy thought the Lady was and how he thought he was going to be when he was her age. In this way, the Lady was the first to draw: they went talking, and the lady went drawing, with the tablet resting on her lap. No signs of impatience were observed; on the contrary, the boy watched closely and helped whenever he thought it was necessary. When they both agreed that the drawing of the boy when he was old was finished, they switched roles. The older Lady handed the tablet to the boy and began to tell him what she looked like when she was 
his age. The Lady told the boy that she could only wear dresses, because, at that time, girls could not wear pants and that led to more talk on the subject and to the exchange of historical knowledge. Throughout the session, they talked about which tools and subtools were most appropriate for drawing what they intended and the interaction with the device was often shared. Regarding the App, and although NOTEPAD+ shares with NOTE HD some problems (such as elements merging with background), it proved to be much more stable. The interaction is intuitive, as the interface is very simple. Although some options are hidden, the access is relatively easy and cannot be made inadvertently, as it demands a long-press. The only problem concerned the touch target area, which was too small for the older Lady fingertips.

\section{Conclusions}

The preliminary study was very important for the validation of data collection protocols and instruments. It was possible to conclude that there is a need to rethink the development questions to ask kids in post JME interviews, since younger children may have difficulties in deepening the introduced themes. Some strategies can include decreasing the child defensiveness by, for example, avoiding open-ended questions beginning with "why" [19], introduce the themes with more age-appropriate vocabulary and sentence structure, use references from the child's personal field of experience, among others.

In what concerns the JME session, the activity proposed to the non-parental related participants proved to be much more interesting than the construction of the family tree, resulting in a more shared content creation process, with more effective collaboration and balanced roles and in a final product that was actually built by the child and the older adult. In this way, and in the main study, the collaborative drawing activity will be proposed to both parental and non-parental related participants and the construction of the family tree will be eliminated.

Regarding the Apps, NOTEPAD+ has proved to be more stable, having a simpler interface and a more intuitive interaction paradigm. Although some of the problems observed during the study could eventually be solved by selecting an App that allow for the use of layers, those are a high-difficulty feature considering the research participants. Therefore, NOTEPAD+ will be the App used in the research future empirical studies. It is expected that these studies' results will allow the outline of a set of recommendations for designing tablets' contents, intended to mediate and support intergenerational interactions.

\section{References}

1. World Health Organization: Ageing and Life Course. Facts about aging. (2014), Retrieved from: http://goo.gl/hzrQlV

2. United Nations: World Population Ageing 2013. United Nations, Department of Economic and Social Affairs, Population Division. ST/ESA/SER.A/348 (2013), Retrieved from: http://goo.gl/wOFHdc 
3. European Union: Population structure and ageing. Eurostat. Statistics Explained. (2014), Retrieved from: http://goo.gl/hgbtSw

4. Strom, RD, Strom, PS.: Assessment of Intergenerational Communication and Relationships. Educational Gerontology; 41(1); p.41-52 (2014).

5. Harwood, J.: Understanding Communication and Aging: Developing Knowledge and Awareness. USA: SAGE Publications, Inc. (2007).

6. Christian, J, Turner, R, Holt, N, Larkin, M, Cotler, JH.: Does intergenerational contact reduce Ageism? When and How Contact Interventions Actually Work? Journal of Arts and Humanities (JAH), 3(1), (2014).

7. Pieri, M, Diamantinir, D.: Young people, elderly and ICT. Procedia - Social and Behavioral Sciences, 2(2), p.2422-2426 (2010).

8. Soliz, J, Harwood, J.: Perceptions of communication in a family relationship and the reduction of intergroup prejudice. Journal of Applied Communication Research, 31(4), p.320345 (2003).

9. Hurme, H., Westerback, S., \& Quadrello, T.: Traditional and New Forms of Contact Between Grandparents and Grandchildren. Journal of Intergenerational Relationships, 8(3), 264-280, (2010), https://doi.org/10.1080/15350770.2010.498739

10. Gutnick, A, Robb, M, Takeuchi, L, Kotler, J.: Always connected: The new digital media habits of young children. New York: The Joan Ganz Cooney Center at Sesame Workshop (2011). Retrieved from: http://goo.gl/s4K009

11. Kaplan, M, Sanchez, M, Shelton, C, Bradley, L.: Using Technology to Connect Generations. Penn State University \& Washington D.C.: Generations United (2013). Retrieved from: http://goo.gl/8UzB6g

12. Castro, M de, Ruiz, B, Sánchez-Pena, J, Crespo, A, Iglesias, A, \& Pajares, J.: Tablets helping elderly and disabled people. In: Bierhoff, I, Nap, H, Rijnen, W, Wichert R, editors. Partnerships for Social Innovation in Europe. Proceedings of the AAL Forum 2011 Lecce. Eersel: Drukkerij Coppelmans; p.237-244 (2011). Retrieved from: http://goo.gl/GnRnHm

13. Takeuchi, L, Stevens, R.: The new coviewing: Designing for learning through joint media engagement. New York: The Joan Ganz Cooney Center at Sesame Workshop (2011). Retrieved from: http://goo.gl/cNM74T

14. Davis, H, Vetere, F, Gibbs, M, Francis, P.: Come play with me: Designing technologies for intergenerational play. Universal Access in the Information Society, 11(1), p.17-29 (2012).

15. Measuring Digital Skills across the EU: EU wide indicators of Digital Competence. European Commission (2014). Retrieved from: https://goo.gl/ZZZg4d

16. The Digital Skills Indicator 2015 - methodological update note. European Commission (2015). Retrieved from: https://goo.gl/cr2Dlh

17. Borges, J, \& Oliveira, L.: Competências infocomunicacionais em ambientes digitais. Observatorio, 5(4), p.291-326 (2011).

18. Green Paper: Digital Literacy. 21st Century Competencies for Our Age: The Digital Age. The Fundamental Building Blocks of Digital Literacy From Enhancement to Transformation. UK Government (2015). Retrieved from: http://dge.mec.pt/estudos-sobre-tecnologiaseducativas

19. Kanfer, R., Eyberg, S. M., \& Krahn, G. L.: Interviewing strategies in child assessment. In C. E. Walker \& M. C. Roberts (Eds), Handbook of clinical child psychology, New York: Wiley, pp. 95-108 (1983). 